Article

\title{
The Impact of Traditional Culture on Farmers' Moral Hazard Behavior in Crop Production: Evidence from China
}

\author{
Liguo Zhang and Xuerong $\mathrm{Li}^{*}$ \\ Institute of Poyang Lake Eco-economics, Jiangxi University of Finance and Economics, Nanchang 330032, China; \\ njlgzhang@163.com \\ * Correspondence: jxsjjj@126.com; Tel.: +86-791-8381-0793
}

Academic Editor: Marc A. Rosen

Received: 19 March 2016; Accepted: 29 June 2016; Published: 8 July 2016

\begin{abstract}
To obtain higher yields, farmers may excessively use pesticides when they grow crops (like rice, vegetables, or fruit), causing moral hazard behavior. This paper examines how Chinese farmers' moral hazard behavior in crop production is influenced by their traditional culture. A semi-parametric logistic model is used to investigate the impact of Chinese traditional culture on farmers' moral hazard behavior. The results reveal that Chinese traditional culture has a positive effect on ameliorating the farmers' excessive use of pesticides in crop production, which leads to a moral hazard in agro-product safety. Specifically, when we control for extraneous variables, the probability of moral hazard decreases by $15 \%$ if farmers consider their traditional culture in their production decisions. Moreover, the probability of moral hazard decreases by $17 \%$ if farmers consider the traditional culture as a powerful restraint regarding the use of pesticides. Our analysis provides some supportive evidence on the effect of Chinese traditional culture on mitigating farmers' excessive use of pesticides.
\end{abstract}

Keywords: moral hazard; Chinese traditional culture; agro-products quality and safety; semi-parametric model; crops production

\section{Introduction}

As important input chemicals in agricultural production, pesticides play an irreplaceable role in promoting agricultural development, increasing production, and farmers' incomes [1,2]. However, pesticides are a toxic chemical substance, and the pollution caused by their excessive use has done serious damage to human health, ecological safety, and the sustainable development of agriculture [3]. According to the Ministry of Agriculture of China in 2014 [4], for the last five years, China's pesticide consumption is approximately 0.31 million tons per year, and the unit area pesticide consumption is $2.5-5$ times higher than the world's average. Pesticide pollution has become a serious problem, especially to the agro-product quality and safety. In March 2015, the "pesticide reduction and efficiency promotion" campaign was undertaken by the Chinese government to reduce the use of pesticides and improve efficiency.

With people's changing consumption preferences, the demand for safe agro-products is increasing significantly. However, because of improper behavior concerning farmers' crop production, such as disobeying the relevant production standards or excessive use of pesticides and additives, agro-products safety incidents occur frequently, mainly characterized by excessive pesticide residue. Given the quality of asymmetric information in the agro-products market, farmers are inclined to use pesticides excessively for more profits, resulting in a large number of products with inferior quality in the markets $[5,6]$. Moral hazard is an economic concept, which states that those who engage in 
economic activities, in order to maximize their own utility, will have inherent incentives to take actions unfavorable for others. As in the agro-products market, there is a principal-agent relationship between buyers and farmers, the buyers (such as agricultural enterprises, wholesalers, supermarkets, and the final consumers) are the principal, while the farmers are the agent. They sign a production contract (sometimes farmers may use certificates instead of contracts, like organic certificates), the buyers commission the farmers to produce agro-products with safe quality, and there are strict regulations on the application of pesticides, including variety, time, and dose. However, as farmers' behaviors cannot be monitored during the production period, in order to get greater yields, they may pursue activities unfavorable to buyers, such as increasing pesticide concentration, adopting banned pesticides, and using pesticides during the harvest period; with farmers' behaviors seriously violating the agreement of the contract, this is thought to be moral hazard behavior (MHB) [7]. Moral hazard hinges crucially on information asymmetry; therefore, the risk-taking party knows more about his (or her) intentions than the party paying for the consequences of the risk [8]. Given the quality information asymmetry in the agro-products market, farmers may excessively use pesticides in the pursuit of higher profits.

Recently, there has been growing interest in studying farmer's MHB. Many analyses have been undertaken to uncover the factors affecting farmers' MHB devoted to crop production. In the literature, factors affecting farmers' MHB cover demographic characteristics, such as age, gender, level of education, risk preference, farmers' cognition, external environment of agricultural production, and characteristics of government regulation, among others [7,9-11]. In China, the government plays a significant role in regulating and supervising farm-level food safety, yet several unsafe food incidents have been uncovered, leading to examination of the causes of these problems. For example, the Chinese government has launched several programs aiming to create a favorable environment for safe farming, including operating quality safety training, providing agricultural technical guidance, and establishing cooperative organizations. Furthermore, the government enacted a series of strict regulatory measures, including an "agro-products quality and safety law", product or place certification, agro-products quality and safety checks, and an agro-products safety traceability system.

In addition to the factors discussed above, it is still debatable whether the Chinese traditional culture is also devoted to farmers' MHB. However, few studies attempt to uncover the relationship between Chinese traditional culture and farmer's MHB. To fill this gap, this study aims to analyze how Chinese traditional culture influences farmers' MHB. Based on the definition proposed by North [12], this paper classifies Chinese traditional culture as an informal institution, which is also known as informal constraints or informal rules, referring to the social rules which gradually formed while people were in the process of long-term social interaction, and it has been recognized and abided by the community vulgarly, including value beliefs, social customs, traditional culture, religious ceremony, moral standards, and so on. Through an investigation in China's rural areas, our study finds that Chinese traditional culture might affect farmers' tendency to conduct MHB in crop production; therefore, this study chooses a semi-parametric logistic model to study the impact of Chinese traditional culture on farmers' MHB. The evidence reveals that Chinese traditional culture has a positive effect on avoiding the MHB devoted to usage of pesticides. The estimated results imply that, when we control for extraneous variables, the probability of moral hazard decreases by $15 \%$ if farmers consider their Chinese traditional culture when making crop production decisions. In addition, the probability of moral hazard decreases by $17 \%$ if farmers consider the Chinese traditional culture as a powerful restraint when using pesticides. Finally, we conduct a sensitivity analysis to compare our model with the conventional logistic one. The results of logistic estimation demonstrate that the impact of regulating government's inspection is less effective than that of advertisement of traditional culture in the sense of reducing moral hazard. This information contradicts the common economic consensus.

This study aims to fill this gap by providing information about how Chinese cultural prosperity contributes to the mitigation of farmer's MHB in crop production. The results also provide useful information for related agricultural and cultural policy decisions. The rest of this paper is arranged as follows. The next section summarizes the relevant literature. Section 3 defines the variables. Section 4 
presents the empirical methodology. Section 5 presents the empirical results and related discussion. The last section concludes the paper and provides important policy implications.

\section{Literature Review}

The main cause of MHB lies in the difference of benefit between principal and agent; as agents' behaviors cannot be monitored, the agents may engage in opportunistic activities. MHB seriously affects the quality and safety of agro-products, and even the physical health of consumers. To find the influencing factors and mechanism of moral hazard, a large number of studies have been conducted in different subject fields, such as behavioral, institutional, and information economics. Researchers have examined farmers' MHB in the field of agro-products quality and safety, with the following results:

\subsection{Discussing What are Moral Hazards Related with Farming}

Moral hazards related with farming are defined as the violation of "production orders", or "hidden action" in the process of agricultural activities, such as the non-observance of agricultural production laws, confrontation with the rules of safe farming, and overuse of agricultural chemicals [7-9,13-15].

\subsection{Analyzing the Main Causes of Farmers' MHB}

By using cost-benefit analysis and the Becker-Stiegler model, as well as principal-agent theory, researchers find that the main causes contributing to farmers' MHB are listed as follows: the asymmetric information between farmers and buyers, the low production cost of unsafe agro-products, light punishment, over-profit orientation, opportunism, market failure involved with agro-products, limitations of government regulation, and so on [16-18].

\subsection{Studying on Impact Factors of Moral Hazard}

Through empirical analysis of farmers' MHB regarding production, scholars propose that the main impact factors are additional incomes of moral hazard, discount rates of future incomes, fines, the probability of being caught, household structure, planting area, pressure from buyers, the distribution channels of agro-products, and so on $[9,13,15,17]$.

\subsection{Studying the Negative Effect of Moral Hazard}

Researchers find that MHB may lead to failure in the agro-products market, leaving a large number of products of inferior quality in the markets while safe agro-products are being expelled from the market and seriously affect consumers' health and safety. As the "lemon market" theory predicts, agro-products with high quality cannot get a high price; therefore, farmers have fewer incentives to engage in safe farming [6,19-21].

\subsection{Researching Countermeasures to Moral Hazard}

The key countermeasures to prevent farmers' MHB include developing agricultural cooperative organizations, establishing agro-product quality control systems, strengthening the supervision of agro-products, and raising the standard of punishment. Moreover, positive-side incentives should also be adopted [13,14,22,23].

As the source of agricultural production, farmers' production behavior is the most important factor affecting agro-products quality and safety [5]. Farmers' production behavior is characterized by decision-making under multiple constraints, such as the farmers' self-discipline, organizational constraints, buyer's constraints, government's constraints, and so on; these factors have been proven by researchers. In fact, farmer behavior is complicated, in addition to the above factors, it may also be related to the long-term social environment, such as village regulations, ethics, social customs, moral standards, and so forth. A lot of research with regard to Chinese traditional culture primarily focuses on its influence on residents' correct outlook on life, worldview, and values [24], whereas less 
attention is given to its effect on farmers' MHB. To explore the factors that affect farmers' MHB, we try to examine how and why Chinese traditional culture affects farmers' MHB.

\section{Data and Variables}

\subsection{Data}

A sampling survey is conducted, as the data used in this study were not available from public databases. The survey was undertaken by combining stratified sampling and random sampling. We stratified the sample according to the planting types and crop yields, as the four provinces being chosen all mainly produce rice or wheat. The data used for this paper were collected from four provinces of rural China, as these provinces are China's major crop producing areas, and they play important roles in crop safety. In each selected province, two counties were randomly selected, and then two towns per county, then about 25 households were randomly picked from each town. The counties we chose in each province all have the same number of towns, so the conditions of a stratified sample are confirmed, and we can use the stratified sample to obtain household survey data. The sample collection was conducted in July and August 2013. The distribution of samples is shown in Table 1.

Table 1. Sampling Survey.

\begin{tabular}{cccc}
\hline Province & County & Issued Questionnaires & Valid Questionnaires \\
\hline \multirow{2}{*}{ Jiangxi } & Yongfeng & 52 & 47 \\
& Ji'an & 55 & 53 \\
\hline \multirow{2}{*}{ Anhui } & Bunan & 56 & 50 \\
& Linquan & 53 & 49 \\
\hline \multirow{2}{*}{ Jiangsu } & Binhai & 50 & 44 \\
& Jianhu & 53 & 49 \\
\hline \multirow{2}{*}{ Henan } & Xinmi & 56 & 50 \\
& Xinzheng & 53 & 47 \\
\hline \multirow{2}{*}{ Total } & & 428 & 389 \\
\hline
\end{tabular}

The survey instrument was a closed-ended questionnaire that was modified from the baseline survey instrument. The household survey used a structured questionnaire to collect data from the selected households including farmers' individual features, household characteristics, farmers' cognition on quality and environment, government regulation characteristics, farmers' cognition on traditional culture, as well as farmers' crop production behavior. In order to improve the effects of the investigation, we carried out a pre-investigation in Nanchang county, Jiangxi province, to check the rationality and feasibility of the questionnaire. According to the problems found in the pre-investigation, we then revised the questionnaire. In order to avoid deviation based on the different culture levels of farmers, the authors participated in recording answers in the questionnaire. The survey resulted in 428 distributed samples, but 39 samples did not provide sufficiently complete information on dependent and explanatory variables to be included in the analysis, so we discarded them, and we finally obtained 389 valid samples. The discarded information do not differ from those adopted for the analysis, and there is no sample selection bias.

\subsection{Variable Selection}

To analyze moral hazard in the use of pesticides by farmers, there are various economic and social factors associated with the benefits and costs regarding violating the rules of using pesticides. The choice of variables should be guided by previous research, economic theory, and the purpose of this research. Under those principles, the variables employed in this study include fifteen explanatory variables (in fact, the survey data contains 38 explanatory variables, and we select 15 of them according 
to the purpose of this study) and one dependent variable; the detailed definitions of each variable are shown in Table 2.

In crop production, in order to improve the effect of pesticides or to get higher yields, farmers may increase pesticide concentration ratios, adopt banned pesticides, or use pesticides during the harvest period. If one or more of the above behaviors occur, they are considered MHB. Therefore, moral hazard $(Y)$ is a binary dependent variable indicating the existence of MHB. There are fifteen independent variables in this paper, including five continuous variables and ten discrete variables. The detailed definitions of each variable are shown in Table 2. Some variables need to be specified. Risk preference $\left(X_{4}\right)$ is a dummy variable to show whether farmers are risk-lovers [25-27]. In our questionnaire, we set one question to measure farmers' risk preference, that is "there are two business program, you can earn two thousand yuan without any risk if you choose the first one, and you may have $50 \%$ probability to earn three thousand yuan or only one thousand yuan if you choose the second one, which one will you choose?". If farmers choose the first one, we classify him (or her) as risk averse, otherwise we classify them as a risk lover (in general, including "risk neutral" is more reasonable, but due to our negligence, we offered only two choices in our questionnaire). Employment $\left(X_{7}\right)$ is a binary variable standing for whether people engaged themselves in non-agricultural employment. Environmental concern $\left(X_{10}\right)$ is a dummy variable to show whether farmers are concerned with environmental protection in the decision of pesticide use. Quality concern $\left(X_{11}\right)$ is a dummy variable to show whether farmers are concerned with the quality and safety of agricultural products. Inspection $\left(X_{12}\right)$ is a dummy variable to show whether government inspection systems are strict. Penalty $\left(X_{13}\right)$ is a dummy variable to show whether the penalty measures are strict. Culture_1 $\left(X_{14}\right)$ is a dummy variable to show whether farmers consider the traditional culture when they make crop production decisions. Culture_2 $\left(X_{15}\right)$ is a dummy variable to show whether farmers consider the traditional culture as a restraint $[28,29]$.

Table 2. Variables' names and definitions.

\begin{tabular}{|c|c|}
\hline Variables & Definitions \\
\hline \multicolumn{2}{|l|}{ Farmers' crops production behavior } \\
\hline Moral hazard behavior $(Y)$ & $\begin{array}{l}\text { A zero-one, discrete variable set equal to } 1 \text { if the farmers carry a } \\
\text { hazardous behavior, such as using banned pesticides. }\end{array}$ \\
\hline \multicolumn{2}{|l|}{ Farmers' individual features } \\
\hline Age of household head $\left(X_{1}\right)$ & The true age of household head (Years) \\
\hline Gender $\left(X_{2}\right)$ & $0=$ Male, $1=$ Female \\
\hline Education $\left(X_{3}\right)$ & $1=$ Illiterate, $2=$ Primary, $3=$ Junior, $4=$ High school, $5=$ College \\
\hline Risk preference $\left(X_{4}\right)$ & $0=$ Risk Aversion, $1=$ Risk lover \\
\hline \multicolumn{2}{|l|}{ Household characteristics } \\
\hline Number of family members $\left(X_{5}\right)$ & Actual family members (Person) \\
\hline Total income $\left(X_{6}\right)$ & Actual family incomes (Yuan) \\
\hline Employment $\left(X_{7}\right)$ & $0=$ No, $1=$ Yes \\
\hline Non-agricultural income $\left(X_{8}\right)$ & Actual non-agricultural income (Yuan) \\
\hline Non-agricultural income share $\left(X_{9}\right)$ & The ratio of Non-agricultural income to total income (\%) \\
\hline \multicolumn{2}{|c|}{ Farmers' cognition on quality and environment } \\
\hline Environmental concern $\left(X_{10}\right)$ & $0=$ Not concern, $1=$ concern \\
\hline Quality concern $\left(X_{11}\right)$ & $0=$ Not concern, 1 = concern \\
\hline \multicolumn{2}{|l|}{ Government regulation characteristics } \\
\hline Inspection $\left(X_{12}\right)$ & $0=$ Not Strict, $1=$ Strict \\
\hline Penalty $\left(X_{13}\right)$ & $0=$ Not Strict, $1=$ Strict \\
\hline \multicolumn{2}{|c|}{ Farmers' cognition on traditional culture } \\
\hline Culture_1 $\left(X_{14}\right)$ & $0=$ No, $1=$ Yes \\
\hline Culture_2 $\left(X_{15}\right)$ & $0=\mathrm{No}, 1=\mathrm{Yes}$ \\
\hline
\end{tabular}

Note: "Culture_1" stands for whether farmers consider the traditional culture when they are making crop production decisions; “Culture_2" stands for whether farmers consider the traditional culture as a restraint in the use of pesticides. 


\subsection{Descriptive Analysis}

\subsubsection{Descriptive Analysis of Dependent Variables}

In accordance with previous studies, farmers' MHB is measured in terms of pesticides used in crop production, where farmers increasing the concentration ratio of pesticides $\left(A_{1}\right)$, adopting banned pesticides $\left(\mathrm{A}_{2}\right)$, or using pesticides during the harvest period $\left(\mathrm{A}_{3}\right)$ in the process of crop production are considered MHB. As long as one or more of the above behaviors occurred, it is considered MHB. Survey data show that the number of MHB is 168 , accounting for $43.2 \%$ of the 389 simples, this means that the problem of MHB is considerably serious in the process of crop production. Table 3 reports the farmers' MHB, the above three behaviors, the number of farmers who increased the concentration ratio of pesticides is the highest at 144, while the other two kinds of behaviors are almost the same. The reason may be that the agricultural production is entirely in the control of farmers, which indicates that it is difficult for the government to regulate food safety. Specifically, the number of farmers with only one of the above behaviors is 76, all of the above three behaviors is $8, A_{1}$ and $A_{2}$ are $42, A_{1}$ and $\mathrm{A}_{3}$ are $30, \mathrm{~A}_{2}$ and $\mathrm{A}_{3}$ are 12 .

Table 3. Moral hazard behavior of farmers.

\begin{tabular}{ccccc}
\hline Happened or Not & $\mathbf{A}_{\mathbf{1}}$ & $\mathbf{A}_{\mathbf{2}}$ & $\mathbf{A}_{\mathbf{3}}$ & Moral Hazard \\
\hline NO $(\mathrm{Y}=0)$ & 245 & 331 & 335 & 221 \\
YES $(\mathrm{Y}=1)$ & 144 & 58 & 54 & 168 \\
\hline
\end{tabular}

\subsubsection{Descriptive Analysis of Independent Variables}

We divide the samples into two groups which, respectively, expressed whether farmers' MHB happened, and furthermore we use a t-test to identify whether variables have significant differences. Table 4 presents the differences in the characteristics of the happened and the not-happened group with their $\mathrm{t}$-values. The $\mathrm{t}$-values indicate that there are significant differences in some of the variables used in the empirical analysis. Specifically, most characteristics of the happened group are lower than the not-happened group. However, the risk preference and gender are all significantly higher factors for the happened group than for the not-happened group. The differences in the mean characteristics between the happened group and the not-happened group indicate that these factors may have impacts on farmers' MHB.

Table 4. Variable differences between the happened and not the happened group.

\begin{tabular}{lcccccc}
\hline \multirow{2}{*}{$\begin{array}{l}\text { Variables } \\
\end{array}$} & Units & \multicolumn{2}{c}{$\begin{array}{c}\text { Happened } \\
(\boldsymbol{n}=\mathbf{1 6 8})\end{array}$} & \multicolumn{2}{c}{$\begin{array}{c}\text { Not Happened } \\
(\boldsymbol{n}=\mathbf{2 2 1})\end{array}$} & \multirow{t}{*}{$\boldsymbol{t}$-Test } \\
\cline { 3 - 6 } & & Mean & SE & Mean & SE & \\
\hline$X_{1}$ (Age of household head) & Years & 52.36 & 9.9 & 52.84 & 11.3 & 0.217 \\
$X_{2}$ (Gender) & - & 1.40 & 0.491 & 1.28 & 0.450 & $0.016^{* *}$ \\
$X_{3}$ (Education) & - & 2.14 & 0.984 & 2.41 & 0.903 & 0.112 \\
$X_{4}$ (Risk preference) & - & 0.29 & 0.455 & 0.18 & 0.384 & $0.010^{* * *}$ \\
$X_{5}$ (Number of family members) & Person & 4.64 & 2.01 & 4.82 & 1.99 & 0.063 \\
$X_{6}$ (Total income) & Yuan & $41,539.1$ & $40,807.3$ & $51,163.3$ & $53,802.2$ & 0.081 \\
$X_{7}$ (Employment) & - & 0.73 & 0.384 & 0.82 & 0.443 & $0.039^{* *}$ \\
$X_{8}$ (Non-agricultural income) & Yuan & $28,427.8$ & $37,843.8$ & $38,915.2$ & $50,206.2$ & 0.351 \\
$X_{9}$ (Non-agricultural income share) & $\%$ & 54.5 & 36.3 & 66.1 & 35.2 & 0.211 \\
$X_{10}$ (Environmental concern) & - & 0.41 & 0.494 & 0.88 & 0.150 & $0.002^{* * *}$ \\
$X_{11}$ (Quality concern) & - & 0.46 & 0.500 & 0.91 & 0.068 & $0.005^{* * *}$ \\
$X_{12}$ (Inspection) & - & 0.44 & 0.498 & 0.81 & 0.382 & $0.001^{* * *}$ \\
$X_{13}$ (Penalty) & - & 0.48 & 0.501 & 0.97 & 0.096 & $0.000^{* * *}$ \\
$X_{14}$ (Culture_1) & - & 0.58 & 0.402 & 0.87 & 0.177 & $0.002^{* * *}$ \\
$X_{15}$ (Culture_2) & - & 0.40 & 0.478 & 0.84 & 0.364 & $0.001^{* * *}$ \\
\hline
\end{tabular}

Note: ${ }^{* * *}$ and ${ }^{* *}$ denotes significance at $1 \%$ and $5 \%$ respectively. 


\subsection{Correlation Analysis}

Table 5 provides the summary statistics of these variables, including the mean, standard deviation, and Pearson's and Spearman's correlations of the samples, to identify possible affecting factors of farmer's MHB. We can see that the moral hazard, total income, non-agricultural income, and risk preference all have lower averages than their standard deviations, suggesting relatively high volatilities. The Pearson's pairwise correlations between the moral hazard dummy and each factor are reported in the last second column of Table 5. The Pearson's correlations vary from -0.630 to 0.131 . The risk preference dummy has the largest correlation (i.e., 0.131), suggesting the stronger positive dependence of moral hazard and risk preference than that of the moral hazard and other factors. The largest negative correlation is detected between the moral hazard dummy and environmental concern, indicating that concern with environmental protection plays an important role in the decision of pesticide use.

Table 5. Summary of statistics.

\begin{tabular}{lccccc}
\hline & Units & Mean & $\begin{array}{c}\text { Standard } \\
\text { Deviation }\end{array}$ & $\begin{array}{c}\text { Pearson's } \\
\text { Correlation }\end{array}$ & $\begin{array}{c}\text { Spearman's } \\
\text { Correlation }\end{array}$ \\
\hline$Y$ (Moral hazard) & - & 0.437 & 0.497 & - & - \\
$X_{1}$ (Age of household head) & Years & 52.820 & 10.720 & -0.023 & -0.031 \\
$X_{2}$ (Gender) & - & 1.331 & 0.471 & 0.123 & 0.123 \\
$X_{3}$ (Education) & - & 2.295 & 0.947 & $-0.142^{* *}$ & $-0.155^{* *}$ \\
$X_{4}$ (Risk preference) & - & 0.227 & 0.420 & $0.131^{* *}$ & $0.131^{* *}$ \\
$X_{5}$ (Number of family members) & Person & 4.750 & 2.084 & -0.046 & -0.052 \\
$X_{6}$ (Total income) & Yuan & $46,960.470$ & $48,733.186$ & $-0.098^{*}$ & $-0.158^{*}$ \\
$X_{7}$ (Employment) & - & 0.780 & 0.413 & $-0.105^{*}$ & $-0.105^{*}$ \\
$X_{8}$ (Non-agricultural income) & Yuan & $34,335.401$ & $45,469.784$ & $-0.115^{*}$ & $-0.115^{*}$ \\
$X_{9}$ (Non-agricultural income share) & $\%$ & 66.547 & 105.172 & $-0.159^{* *}$ & $-0.210^{* *}$ \\
$X_{10}$ (Environmental concern) & - & 0.731 & 0.444 & $-0.630^{* *}$ & $-0.630^{* *}$ \\
$X_{11}$ (Quality concern) & - & 0.762 & 0.426 & $-0.622^{* *}$ & $-0.622^{* *}$ \\
$X_{12}$ (Inspection) & - & 0.649 & 0.478 & $-0.389^{* * *}$ & $-0.389^{* * *}$ \\
$X_{13}$ (Penalty) & - & 0.767 & 0.423 & $-0.601^{* * *}$ & $-0.601^{* * *}$ \\
$X_{14}$ (Culture_1) & - & 0.798 & 0.402 & $-0.480^{* * *}$ & $-0.480^{* * *}$ \\
$X_{15}$ (Culture_2) & - & 0.649 & 0.478 & $-0.465^{* * *}$ & $-0.465^{* * *}$ \\
\hline
\end{tabular}

Note: "Culture_1" stands for whether farmers consider the traditional culture into when they are making crop production decisions. "Culture_2" stands for whether farmers consider the traditional culture as a restraint in the use of pesticides. ${ }^{* * *}, * *$, and ${ }^{*}$ denotes significance at $1 \%, 5 \%$, and $10 \%$, respectively.

\section{Methodology}

Our study aims to reveal whether Chinese traditional culture mitigates the moral hazard with regard to the farmer in the excessive use of pesticides. As this study indexes the attribute of moral hazard by means of a binary variable, the use of a conventional regression for a continuous dependent variable may result in a misleading inference. To address this concern, we use the logistic model, which remains the most widely used parametric method for the estimation of binary dependent variables. This model depends on two assumptions: a known index, which is assumed to influence choice, and a known parametric form for a distribution function, which is assumed to yield choice probabilities. The traditional parametric logistic model approach to model binary choice is as follows:

$$
\mathrm{E}(Y \mid X=\mathrm{x})=\operatorname{Pr}(Y=1 \mid X)=\mathrm{F}(X \beta)=\frac{\exp (X \beta)}{1+\exp (X \beta)}
$$

where the variable $Y$ denotes the binary dependent variable with $Y=1$, indicating the existence of moral hazard, and $X$ stands for the independent variables including $\left\{X_{p} ; p=1, \ldots, 15\right\}$, which are listed in Section 3.2. The estimation problem is to estimate the unknown parameters $\beta$. F is the cumulative logistic distribution function. The estimation is typically facilitated by the maximum likelihood method. 
The fitted models can be interpreted and estimated efficiently if the underlying assumptions are correct. However, if the model specifications are not satisfied, parametric estimates may be inconsistent and give a misleading regression result. It is possible to relax the restrictive assumption of the functional form by using either semi-parametric or nonparametric models. In these types of models, the functional form is unknown. The problems of estimating semi-parametric and nonparametric binary response models have generated considerable interest since the 1990s. There exists a rich literature of the semi-parametric estimation of binary response models, including Coslett [30], Manski [31], Rudd [32], Coslett [33], and so on. Pagan and Ullah [34] gave a recent survey of semi-parametric approaches to the estimation of binary response models. The semi-parametric logistic model generalizes a parametric logistic model by expanding the linear argument $(X \beta)$ to a partial linear argument $(X \beta+\mathrm{m}(Z))$. The model expression is given as follows:

$$
\mathrm{E}(Y \mid X=\mathrm{x})=\operatorname{Pr}(Y=1 \mid X)=\mathrm{F}(X \beta+\mathrm{m}(Z))=\frac{\exp (X \beta+\mathrm{m}(Z))}{1+\exp (X \beta+\mathrm{m}(Z))}
$$

where $F($.$) is a known function and m($.$) is an unknown function. X$ contains $\left\{X_{4}, X_{10} \ldots, X_{15}\right\}$ and $Z$ includes $\left\{X_{1} \ldots X_{3}, X_{5} \ldots X_{9}\right\}$ (this study categorizes the explanatory variables into two groups: parametric and nonparametric groups. The parametric group contains variables associated with important household characteristics, government regulation characteristics, and traditional culture, whereas the nonparametric one contains the rest of explanatory variables). This model allows for the modeling of the influence of a part the explanatory variables, $\mathbf{Z}$, in a nonparametric way. The estimation process uses the method proposed by Severini and Staniswalis [35]. The method starts from fixing a value of $\beta$ and to estimate a least favorable nonparametric function $m_{\beta}(\cdot)$. The estimated $m_{\beta}(\cdot)$ is then used to construct the profile likelihood for $\beta$. As addressed in Severini and Staniswalis [35], the nonparametric function $\mathrm{m}($.$) can be consistently estimated by \hat{m}(\cdot)=\hat{m}_{\hat{\beta}}(\cdot)$. The profile likelihood function is given by:

$$
\ell\left(Y, v_{\beta}, \theta\right)=\sum_{\mathrm{i}=1}^{\mathrm{N}} \ell\left(Y_{i}, \mathrm{~F}\left(X_{\mathrm{i}} \beta+\mathrm{m}_{\beta}\left(\mathrm{Z}_{\mathrm{i}}\right)\right), \theta\right)
$$

where $Y=\left(\begin{array}{c}Y_{1} \\ \cdot \\ \cdot \\ \cdot \\ Y_{N}\end{array}\right)$ and $v_{\beta}=\left(\begin{array}{c}\mathrm{F}\left(X_{1} \beta+\mathrm{m}_{\beta}\left(\mathrm{Z}_{1}\right)\right) \\ \cdot \\ \cdot \\ \cdot \\ \mathrm{F}\left(X_{\mathrm{N}} \beta+\mathrm{m}_{\beta}\left(\mathrm{Z}_{\mathrm{N}}\right)\right)\end{array}\right)$. We maximize Equation (3) to estimate $\beta$

On the other hand, the smoothed likelihood is used to estimate the nonparametric function $m_{\beta}(Z)$ :

$$
\ell_{\mathrm{s}}\left(Y, v_{\mathrm{m}_{\beta}(\mathrm{Z})}, \theta\right)=\sum_{\mathrm{i}=1}^{\mathrm{N}} \ell\left(Y_{\mathrm{i}}, \mathrm{F}\left(X_{\mathrm{i}} \beta+\mathrm{m}_{\beta}(\mathrm{z})\right), \theta\right) \cdot \mathrm{K}\left(\frac{\mathrm{z}-\mathrm{Z}_{\mathrm{i}}}{\mathrm{s}}\right),
$$

where $\mathrm{K}(\cdot)$ is a Gaussian kernel function and $\mathrm{s}$ is the bandwidth (the details of nonparametric estimation can be found in Li and Rachine [36]). The optimal $m_{\beta}(z)$ can then be obtained by solving the equation:

$$
0=\sum_{i=1}^{N} \ell^{\prime}\left(Y_{i}, F\left(X_{i} \beta+m_{\beta}(z)\right), \theta\right) \cdot K\left(\frac{z-Z_{i}}{s}\right)
$$

\section{Results and Discussion}

This section begins with data analysis and follows with semi-parametric estimation of the logistic model. A conventional logistic estimator is additionally used for comparison. In China, the government prefers to use formal institutions to constrain farmers' behavior; therefore, our study will also compare the effect of formal institutions with informal institutions on MHB (in this paper, government regulations belong to formal institutions, while traditional culture belongs to informal institutions). 


\subsection{Estimation of Semi-Parametric Logistic Regression}

In this section, we report the semi-parametric estimates of the logistic regression by Equation (2). The factors that affect farmers' MHB are divided into important and non-important variables, which are inserted into the parametric and non-parametric parts of the semi-parametric logistic model, respectively. Our purpose is to find the variables that have a significant impact on farmers' $\mathrm{MHB}$, and the corresponding regression coefficients. As the estimated parameters can be easily transformed to the partial effect, this study provides the estimates of partial effects of important variables, which are categorized into the parametric part (due to the lack of a straightforward effects estimate, this study does not discuss the marginal effects of variables in the nonparametric section).

We write the model into the $\mathrm{R}$ programming language, and draw the regression results of the model with the aid of the R 3.2.2 software (Invented by Oakland University's Ihaka Ross and Gentleman Robert). The final regression results are shown in Table 6. It shows that risk preference $\left(X_{4}\right)$, environmental concern $\left(X_{10}\right)$, quality concern $\left(X_{11}\right)$, inspection $\left(X_{12}\right)$, penalty $\left(X_{13}\right)$, culture_1 $\left(X_{14}\right)$, and culture_2 $\left(X_{15}\right)$ are significantly related to farmers' MHB, (while the variables that are not significant at the $10 \%$ level as shown in Table 4 , are not shown in Table 6). As researchers have verified some of the factors, we hope to examine how the Chinese farmers' MHB in crop production is influenced by their traditional culture. Section 5.1.1 discusses the regression results of traditional culture cognition variables, Section 5.1.2 is a comparison between formal and informal institutions, and other factors are discussed in Section 5.1.3.

Table 6. Semi-parametric logistic regression.

\begin{tabular}{lc}
\hline \multicolumn{1}{c}{ Variables } & Partial Effect \\
\hline$X_{4}$ (Risk preference) & $0.155^{* * *}$ \\
$X_{10}$ (Environmental concern) & $-0.299^{* * *}$ \\
$X_{11}$ (Quality concern) & $-0.299^{* * *}$ \\
$X_{12}$ (Inspection) & $-0.132^{* *}$ \\
$X_{13}$ (Penalty) & $-0.346^{* * *}$ \\
$X_{14}$ (Culture_1) & $-0.149^{* *}$ \\
$X_{15}$ (Culture_2) & $-0.167^{* * *}$ \\
Note: $^{* * *}$ and ${ }^{* *}$ denotes significance at $1 \%$ and $5 \%$ respectively.
\end{tabular}

\subsubsection{Regression Results of Traditional Culture Cognition Variables}

As demonstrated in Table 6, the Culture_1 dummy is statistically significant with farmers' MHB, and the estimated marginal effect of the Culture_1 dummy is -0.149 . This implies that when we control for extraneous variables, the probability of moral hazard decreases by $15 \%$ if farmers consider the traditional culture when they are making crop production decisions. The Culture_2 dummy is also statistically significant with farmers' MHB, and the estimated marginal effect of the Culture_2 dummy is -0.17 . This implies that when we control for extraneous variables, the probability of moral hazard decreases by $17 \%$ if farmers consider the traditional culture as a powerful restraint when using pesticides. The evidence reveals that Chinese traditional culture has a positive effect on avoiding the moral hazard with regard to the farmer in the excessive use of pesticides.

Why can Chinese traditional culture restrict farmers' behavior? Chinese traditional culture was fostered in an agricultural society, including many traditional ideologies such as the golden mean, harmony, patriotism, self-improvement, moral standards, honesty, loyalty, cooperation, and solidarity. Conveying the harmonious relationship between human beings and nature, Chinese traditional culture has played a major role in improving farmer quality, regulating farmer behaviors, and developing rural society and economy. Farmers with high moral standards will internalize the excellent traditional culture, and this becomes a constraint factor on behavior. Therefore, under the influence of Chinese traditional culture and pushed by inner moral constraints, farmers will hesitate 
to perform harmful agricultural activities, such as increasing the concentration ratio of pesticides or using banned pesticides.

\subsubsection{Comparison of the Effect of Formal Institutions and Informal Institutions on MHB.}

In China, farmer's behaviors are constrained by formal and informal institutions. Specifically, government regulations (such as inspection, penalty, and law) belong to formal institutions, while traditional culture is considered an informal institution. China mainly depends on formal institutions to constrain farmers' behaviors. Therefore, it is necessary to verify whether the formal institutions (inspections, penalties) constrain farmers' behaviors.

As discussed in Starbird [37], legalistic terms are the most powerful instruments to mitigate the moral hazard, as they are compulsory. We examine whether the government's inspection mechanism is strict and whether the penalty system really works. In principle, the primary findings in our study confirm the theory. As can be seen from Table 6, inspection $\left(X_{12}\right)$ is statistically significant with farmers' MHB, and the estimated marginal effect is -0.132 . This implies that the probability of moral hazard decreases by $13 \%$ when the governmental inspection mechanism becomes strict while the other variables remain constant. Farmers will be inclined to control the use of pesticides, as they are conscious that the possibility of agro-products being detected is increasing. Penalty $\left(X_{13}\right)$ is also statistically significant with farmers' $\mathrm{MHB}$, and the estimated marginal effect -0.346 . Implying that the probability of moral hazard decreases by $34.6 \%$ if farmers who are caught by the supervision department are eventually punished, while the other variables remain constant. Moreover, our findings address the importance of the execution of the punishment system. The estimated marginal effect of the penalty variable, -0.346 , is twice as much as that of the inspection variable. In China, the penalty measures of the government are very effective in regulating the behavior of farmers. If one farmer who disobeys the rules of crop production pays a large fine, most farmers will adjust their application of pesticides accordingly. As a result, the MHB is going to decrease, in comparison with a light penalty. After comparing with the informal institutions (Chinese traditional culture), we find that formal institutions (inspection and penalty) are more effective in constraining of farmers' MHB.

\subsubsection{Regression Results of Different Independent Variables}

As numbers of samples for A2 (58 samples) and A3 (54 samples) are not enough to provide a consistent estimation of the semi-parametric model, this study only considers the A1 type. The results are reported in Table 7. In our paper, A1 represents the behaviors of farmers increasing pesticide concentration ratios while producing crops. From Table 7 we know that Chinese traditional culture is also statistically significant with farmers' above behavior, but the partial effect is lower than that of moral hazard behavior (as can be seen from Table 6), the reason may be that the pesticide concentration ratio is hard to control, and some farmers' behaviors have certain randomness. However, under the influence of Chinese traditional culture, there are still some farmers properly using pesticides; they do not increase the pesticide concentration ratio while producing crops.

Table 7. Semi-parametric logistic regression of independent variables (type A1).

\begin{tabular}{lc}
\hline \multicolumn{1}{c}{ Variables } & Partial Effect \\
\hline$X_{4}$ (Risk preference) & 0.115 \\
$X_{10}$ (Environmental concern) & $-0.290^{* * *}$ \\
$X_{11}$ (Quality concern) & $-0.135^{*}$ \\
$X_{12}$ (Inspection) & -0.112 \\
$X_{13}$ (Penalty) & -0.146 \\
$X_{14}$ (Culture_1) & $-0.126^{* *}$ \\
$X_{15}$ (Culture_2) & $-0.071^{* * *}$ \\
Note: $* * * * *$ and ${ }^{*}$ denotes significance at $1 \%, 5 \%$, and $10 \%$, respectively.
\end{tabular}




\subsubsection{Regression Results of Other Factors}

In the literature, there have been several findings of how risk preference and farmers' attitudes towards the environment influence farmers' MHB in the use of pesticides (including Gleen [15], Philippe [18], and Teresa [38], Arthur [39], Salvatore [40]). Consistent with previous studies, our results find that the odds of MHB will decrease if farmers are concerned with environmental protection.

As demonstrated in Table 6, risk preference $\left(X_{4}\right)$ is statistically significant with farmers' MHB, and the estimated marginal effect of risk preference dummy is 0.155 , implying that the probability of moral hazard increases by $15.5 \%$ if farmers are risk-lovers. The reason could be that those farmers are not concerned about the negative effects of the excessive use of pesticides on environmental pollution. Therefore, in order to save the time of agricultural production, farmers dare to take risks. That is, risk-lover farmers have a higher inclination of moral hazard. Environmental concern $\left(X_{10}\right)$ is also statistically significant with farmers' MHB and the estimated marginal effect of environmental concern dummy is -0.299 . This suggests that the probability of moral hazard decreases by $29.9 \%$ if farmers are concerned about environmental pollution in rural areas. This indicates that the farmers concerned about environmental pollution in rural areas have less of a chance of MHB than those who are not. It may be that farmers who are concerned about environmental pollution in rural areas know the harm of excessive use of pesticides on the rural ecological environment, so those farmers will regulate the use of pesticides. Quality concern $\left(X_{11}\right)$ is also statistically significant with farmers' MHB and the estimated marginal effect of quality concern dummy is -0.299 . This implies that the probability of moral hazard decreases by $29.9 \%$ if farmers are concerned about the quality of agro-products. It is possible that the farmers concerned about the quality of agro-products have lower probability of moral hazard than those who are not. It could be possible that farmers who are concerned about the quality of agro-products are aware of the side effects of excessive use of pesticides on agro-products quality and safety, for example, excessive pesticide residues, so farmers will regulate the use of pesticides.

\subsection{Sensitivity Analysis}

In 5.1, the estimation of a semi-parametric logistic regression is conducted as we argue that there may exist model misspecification. For comparison, we also report the estimations of a parametric logistic regression of Equation (1) which assumes each variable should have a linear relationship with the dependent variable.

The estimates of parameters are demonstrated in Table 8. It can be observed that the odds ratios vary largely from 0.011 to 4.156 . The risk preference has the highest odds ratios, 4.156 , implying that the farmers with risk- taking propensity are 4.156 times more likely to use pesticides excessively.

The risk of moral hazard is 0.133 times greater for farmers who take the traditional culture into account when they using pesticides than those who do not. On the other hand, the risk of moral hazard is 0.279 times greater when the government's inspection mechanism is strict than when it is not strict. Comparing these two cases, the effect of regulating government's inspection is less effective than that of the advertisement of traditional culture regarding reducing moral hazard. However, this result seems to contradict the conventional economic senses. Thus, the model misspecification may yield incorrect inferences about the MHB.

Table 8. Parametric logistic regression.

\begin{tabular}{lc}
\hline \multicolumn{1}{c}{ Variables } & Odds Ratios \\
\hline$X_{4}$ (Risk preference) & $4.156^{* * *}$ \\
$X_{10}$ (Environmental concern) & $0.036^{* * *}$ \\
$X_{11}$ (Quality concern) & $0.011^{* * *}$ \\
$X_{12}$ (Inspection) & $0.279^{* * *}$ \\
$X_{13}$ (Penalty) & $0.028^{* * *}$ \\
$X_{14}$ (Culture_1) & $0.133^{* * *}$ \\
$X_{15}$ (Culture_2) & $0.313^{* *}$ \\
\cline { 2 - 2 } Note: & $* * *$ and ${ }^{* *}$ denote significance at $1 \%$ and $5 \%$ respectively.
\end{tabular}




\subsection{Discussion}

As the quality and safety incidents in agro-products are highly related to the farmers' MHB, many researchers try to uncover the factors that impact farmers' MHB. This study aims to analyze how Chinese traditional culture impacts farmers' MHB. From the above analysis, we know that Chinese traditional culture has a positive effect on avoiding the MHB with regard to the excessive use of pesticides. The results of this paper contribute to the literature on factors influencing farmers' MHB from a new perspective. Meanwhile, it is of great importance to guarantee agro-products quality and safety at the source. Compared with previous research, this paper analyzes the farmers' MHB restricting factors and puts forward policy implications, and we find a new factor restricting farmers' behavior. This is part of the research of farmers' behavior, which enriched the research of farmers' $\mathrm{MHB}$, and deepened the understanding of the Chinese farmer's economic and social behavior.

\section{Conclusions and Implications}

Agricultural chemicals, such as pesticides, play a critical role in crop production and food safety in China. However, with the purpose of getting higher yields or better pesticide effect, farmers may excessively use pesticides, causing the occurrence of MHB. Farmers' MHB has resulted in serious agro-product quality and safety problems. Regulating pesticide usage to provide safe and nutritional agro-products remains one of the meaningful projects in 21st-century China. Therefore, finding out the factors affecting farmers' MHB is of great importance. As other factors have been verified by researchers, this study examined how the Chinese traditional culture influences farmers' MHB in the use of pesticides based on a household survey in four provinces of rural China. The previous research adopted binary logistic models to study farmers' MHB, but if the model specifications are not satisfied, parametric estimates may be inconsistent and give a misleading regression result. Instead we conduct semi-parametric estimation of a logistic model to reveal how the Chinese traditional culture influences farmers' MHB. This helps in estimating the true effect of factors related to farmers' MHB.

Three main conclusions can be drawn from the results of this study. First, we find that the Chinese traditional culture has a significant impact on avoiding the moral hazard with regard to the excessive use of pesticides. The estimated marginal effect of the Culture_1 dummy is -0.1468 . This implies that when we control for extraneous variables, the probability of moral hazard decreases by $15 \%$ if farmers consider the traditional culture when making crop production decisions. The estimated marginal effect of the Culture_2 dummy is -0.17 . This implies that when we control for extraneous variables, the probability of moral hazard decreases by $17 \%$ if farmers consider the traditional culture as a powerful restraint when using pesticides. Second, this study suggests that formal institutions are more effective in constraining farmers' production behavior, which helps to reduce the probability of moral hazard. Third, after comparing the estimated results with a conventional logistic model, we find that the model misspecification may yield incorrect inferences about the moral hazard. The reason could be that some variables are not necessarily linear with dependent variables, but we assume that there is a linear relationship between them.

Agriculture is largely affected by weather fluctuations and climate changes, and it is full of risks. There are abundant public risk management programs both in developed and developing countries, it offers useful risk management strategies, such as crop insurance subsidies and crop disaster payments. However, the risk programs, like crop insurance subsides, may cause farmers to increase chemical use, which may also promote environmental degradation. A vast literature focuses on the potential environmental impacts of government-sponsored risk management programs [7,9,10,41,42]. Our study examines the relationship between Chinese traditional culture and farmers' MHB in crop production. The results show that the Chinese traditional cultures has a positive effect on avoiding the MHB with regard to the excessive use of pesticides, and it provides a new idea of risk management. It is necessary to compare our results with the existing literatures [43-46]. The existing literature mainly evaluated the effects of public risk management policies, the results showing that the risk management programs may incentivize activities harmful for the environment, while our study mainly examines how Chinese 
farmers' moral hazard behavior in crop production is influenced by traditional culture, and our results confirm the conventional view that Chinese traditional culture helps to guide farmers to adopt positive behaviors, such as environmental friendly behavior.

This study has important policy implications. First, as government regulation measures are more effective, in order to have a long-term and more significant impact on farmers' MHB, government should formulate and perfect relevant policies, such as improving the frequency of random inspections, intensifying the penalty, and strengthening market supervision for agricultural inputs. Meanwhile, as most farmers have little knowledge about production safety or environmental protection, training and guidance is also needed. Second, Chinese traditional culture has a significant impact on avoiding the MHB devoted to usage of pesticides, so we should pay more attention to the important role of Chinese traditional culture. Therefore, it is necessary to make full use of Chinese traditional culture in regulating farmers' behavior. For example, we can spread the Chinese traditional culture to farmers by mobile phone, TV, newspaper, and other forms. By strengthening the traditional culture education, we can enhance farmers' moral sentiments, moral standards, conscience, and social responsibility, enabling farmers to achieve harmony between human beings and nature. Considering that farmers' attitudes towards agro-products and environmental protection have a significant effect on farmers' $\mathrm{MHB}$, it is crucially important to improve farmers' quality, safety, and environmental consciousness. Village committees can also regularly publicize some agro-product quality and safety incidents to farmers. The public can also inform farmers of the importance of environmental protection on their health, on the quality and safety of agro-products, and the sustainable development of agriculture. In all, our purpose is to guide farmers to regulate the use of pesticides.

While this study has made significant advancements in knowledge about the impact of Chinese traditional culture on farmers' MHB it, nevertheless, have its limitations. That is, the number of samples is not large enough, we did not compare the farmers' MHB of different regions, and we do not consider other factors such as agricultural organizations, buyers, or the farmers' self-discipline, but these factors may significantly affect farmers' MHB. There are still unresolved questions with this paper. For example, we can refine the influence of Chinese traditional culture on farmers' behavior into constraints and incentives. In addition, we can expand the investigation province and increase the sample to achieve better statistical testing and, hence, we can study whether the influence of Chinese traditional culture varies with different rural economic development levels.

Acknowledgments: We are grateful to the two anonymous referees and the editor for their helpful comments on the manuscript. Meanwhile, the support of National Natural Science Foundation of China (71263018), China Postdoctoral Foundation (2013T60236, 2012M510700), Jiangxi Social Science Planning Fund (13GL06,), Major Project of Economic and Social Development of Jiangxi Province, China (16ZD06), Collaborative Innovation Center of Sustainable Development Decision Support for Modern Agriculture and Its Advantage Industries in Jiangxi Province (XDNYA1507) and Postgraduate Innovation Project of Jiangxi Province (YC2015-B060) is gratefully acknowledged.

Author Contributions: XueRong Li collects the data. Both LiGuo Zhang and XueRong Li analyze results with economic interpretation. Both authors read and approved the final manuscript.

Conflicts of Interest: The authors declare no conflict of interest.

\section{References}

1. Stevens, R.E.; Mcewen, F.L.; Stephenson, G.R. The use and significance of pesticides in the environment. J. Range Manag. 1981, 7, 34-52. [CrossRef]

2. Warren, L.M. Healthy crops or healthy people? Balancing the needs for pest control against the effect of pesticides on bystanders. J. Environ. Law 2009, 3, 483-499. [CrossRef]

3. Doris, S.; Jeffrey, M.; Michael, W.; Jack, H. Environmental impacts from pesticide use: A case study of soil fumigation in Florida tomato production. Int. J. Environ. Res. Public Health 2011, 8, 4649-4661.

4. China's Agriculture Ministry. China's Average Amount of Pesticide Usage is 2.5 to 5 Times Higher than that of the World. Available online: http:/ / www.moa.gov.cn/ (accessed on 7 July 2016). 
5. McCluskey, J.J. A game theoretic approach to organic foods: An analysis of asymmetric information and policy. Agric. Resour. Econ. Rev. 2000, 1, 1-9.

6. Perloff, J.M.; Rausser, G.C. The effect of asymmetrically held information and market power in agricultural markets. Am. J. Agric. Econ. 1983, 65, 325-336. [CrossRef]

7. Smith, V.H.; Goodwin, B.K. Crop insurance, moral hazard, and agricultural chemical use. Am. J. Agric. Econ. 1996, 2, 428-438. [CrossRef]

8. Quiggin, J.; Karagiannis, G.; Stanton, J. Crop insurance and crop production: An empirical study of moral hazard and adverse selection. Aust. J. Agric. Resour. Econ. 1993, 2, 95-113. [CrossRef]

9. Horowitz, J.K.; Lichtenberg, E. Insurance, moral hazard and chemical use in agriculture. Am. J. Agric. Econ. 1993, 4, 926-935. [CrossRef]

10. Torkamani, J.; Mousavi, S.N. Effects of crop insurance on productivity and risk management: A case study of fars province. J. Agric. Econ. Res. 2011, 1, 1-26.

11. Santeramo, F.G.; Goodwin, B.K.; Adinolfi, F.; Capitanio, F. Farmer participation, entry and exit decisions in the Italian crop insurance program. J. Agric. Econ. 2016, 3, 1-29.

12. North, D. System, Institutional Change and Economic Performance; Cambridge University Press: Cambridge, UK, 1990.

13. Starbird, S.A. Moral hazard, inspection policy and food safety. Rev. Agric. Econ. 2005, 1, 15-27. [CrossRef]

14. Norbert, H. A model-based approach to moral hazard in food chains. Ger. J. Agric. Econ. 2004, 5, $192-205$.

15. Glenn, S. Efficient waste? Why farmers over-apply nutrients and the implications for policy design. Rev. Agric. Econ. 2005, 4, 542-557.

16. Roberts, M.J.; Key, N.; Donoghue, E.O. Estimating the extent of moral hazard in crop insurance using administrative data. Rev. Agric. Econ. 2006, 3, 381-390. [CrossRef]

17. Adam, O.; Tim, H.; David, C. Moral hazard, risk aversion and compliance monitoring in agro-environmental policy. Eur. Rev. Agric. Econ. 2008, 3, 329-347.

18. Philippe, B.; Alban, T. Regulating nitrogen pollution with risk-averse farmers under hidden information and moral hazard. Am. J. Agric. Econ. 2006, 1, 57-72.

19. Christoph, S.; Matin, Q.; Maximo, T.; Angelino, V. Contract farming and small-holder incentives to produce high quality: Experimental evidence from the Vietnamese dairy sector. Agric. Econ. 2013, 3, 297-308.

20. Coble, K.T.O.; Knight, R.D.; Williams, J.R. An expected indemnity approach to the measurement of moral hazard in crop insurance. Am. J. Agric. Econ. 1997, 1, 216-226. [CrossRef]

21. Bharat, R. Supply response to agricultural insurance: Risk reduction and moral hazard effects. Am. J. Agric. Econ. 2003, 10, 914-925.

22. Martin, D.; Michael, L. Social norms and moral hazard. Econ. J. 2001, 7, 506-525.

23. Milton, B. The role of public policy and agricultural risk management in food security public policy: Implications for food security. China Agric. Econ. Rev. 2011, 4, 25-31.

24. Jenkins, T.N. Chinese traditional thought and practice: Lessons for an ecological economics worldview. Ecol. Econ. 2002, 1, 39-52. [CrossRef]

25. Goodwin, B.K. Payment limitations and acreage decisions under risk aversion: A simulation approach. Am. J. Agric. Econ. 2009, 1, 19-41. [CrossRef]

26. Wang, M.; Ye, T.; Shi, P. Factors affecting farmers' crop insurance participation in China. Can. J. Agric. Econ. 2015, 1, 1-14. [CrossRef]

27. Ye, T.; Liu, Y.; Wang, J.; Wang, M.; Shi, P. Farmers' crop insurance perception and participation decisions: Empirical evidence from Hunan China. J. Risk Res. 2016, 1, 1-14. [CrossRef]

28. Gu, M.Y. An analysis of the impact of traditional Chinese culture on Chinese education. Front. Educ. China 2006, 2, 169-190. [CrossRef]

29. Li, L. How has Chinese traditional culture an impact on China's intellectual property legal system? Would this influence be a problem in the protection of folklore by the Intellectual property legal system? Int. J. Interdiscip. Soc. Sci. 2009, 1, 269-282.

30. Coslett, S.R. Distribution-Free maximum likelihood estimation of the binary choice mode. Econometrics 1983, 51, 765-782. [CrossRef]

31. Manski, C.F. Semiparametric analysis of binary response from response-based samples. J. Econ. 1986, 1, 31-40. [CrossRef] 
32. Ruud, P. Consistent estimation of limited dependent variable models despite misspecification of distribution. J. Econ. 1986, 32, 157-187. [CrossRef]

33. Coslett, S. Semiparametric estimation of a regression model with sampling selectivity. Nonparametr. Semiparametr. Methods Econ. Stat. 1991, 7, 175-197.

34. Pagan, A.; Ullah, A. Nonparametric Econometrics; Cambridge University Press: Cambridge, UK, 1999.

35. Severini, T.A.; Staniswalis, J.G. Quasi-likelihood estimation in semiparametric models. J. Am. Stat. Assoc. 1994, 89, 501-511. [CrossRef]

36. Li, Q.; Racine, J.S. Nonparametric Econometrics: Theory and Practice; Princeton University Press: Princeton, NJ, USA, 2007.

37. Starbird, S.A. Testing errors, supplier segregation, and food safety. Agric. Econ. 2007, 3, 325-334. [CrossRef]

38. Teresa, S.; Zilbermann, D.; José, M.G. Differential uncertainties and risk attitudes between conventional and organic producers: The case of Spanish arable crop farmers. Agric. Econ. 2008, 2, 219-229.

39. Arthur, P.J.M.; Peter, O. Certification of markets, markets of certificates: Tracing sustainability in global agro-food value chains. Sustainability 2015, 7, 12258-12278.

40. Salvatore, C. GM crops, organic agriculture and breeding for sustainability. Sustainability 2014, 7, 4273-4286.

41. Xu, R.; Kuang, R.P.; Pay, E.; Dou, H.; Geert, R. Factors contributing to overuse of pesticides in western China. Environ. Sci. 2008, 4, 235-249. [CrossRef]

42. Menapace, L.; Colson, G.; Raffaelli, R. Risk aversion, subjective beliefs, and farmer risk management strategies. Am. J. Agric. Econ. 2013, 2, 384-389. [CrossRef]

43. Capitanio, F.; Felice, A.; Santeramo, F.G. Environmental implications of crop insurance subsidies in Southern Italy. Int. J. Environ. Stud. 2015, 1, 179-190. [CrossRef]

44. Fabian, C.; Felice, A.; Santeramo, F.G. Crop insurance subsidies and environmental externalities: Evidence from southern Italy. Outlook Agric. 2014, 4, 253-258.

45. Santeramo, F.G.; Pasquale, J.D.; Contò, F.; Tudisca, S.; Sgroi, F. Analyzing risk management in Mediterranean countries: The Syrian perspective. New Medit 2012, 11, 35-40.

46. Santeramo, F.G.; Capitanio, F.; Adinolfi, F. Integrating agricultural risks management strategies in selected EU Partner Countries: Syria, Tunisia, Turkey. Romanian J. Eur. Aff. 2014, 3, 22-35. [CrossRef]

(C) 2016 by the authors; licensee MDPI, Basel, Switzerland. This article is an open access article distributed under the terms and conditions of the Creative Commons Attribution (CC-BY) license (http://creativecommons.org/licenses/by/4.0/). 